\title{
The Effect of the Addition of Turbo cyclone on the Inlet Air on Torque and Power in the Toyota Avanza 1300 CC
}

\section{Pengaruh Penambahan Turbo cyclone pada Saluran Udara Masuk terhadap Torsi dan Daya pada Mobil Toyota Avanza 1300 CC}

\author{
Ilham Zikri ${ }^{1}$, Remon Lapisa ${ }^{1}$
}

\begin{abstract}
The decrease in the performance of the vehicle is influenced by several factors such as low air pressure entering the throttle body. The purpose of this research is to improve vehicle performance again. This study used an experimental method conducted at the UNP Automotive Engineering Vehicle Testing Workshop using a Toyota Avanza 1300 CC vehicle, power and torque research was carried out by adding a turbo cyclone. Research data collection was carried out three times in each test. The results of research that has been carried out on the Toyota Avanza 1300 CC vehicle. 1) Installation of a turbo cyclone at a slope of 550 is the biggest increase in power, which is $3.3 \mathrm{Kw} / 4.422 \mathrm{Hp}$.2) Installation of a turbo cyclone at a slope of 650 , the largest increase in torque, which is $7.3 \mathrm{Nm}$. From the use of a turbo cylone so as to make air pressure increase, it affects torque and power.
\end{abstract}

\section{Keywords}

Toyota Avanza 1300 CC, Turbo cyclone, Torque, Power, Pressure Drop

\begin{abstract}
Abstrak
Penurunan kinerja dari kendaraan dipengaruhi beberapa faktor seperti rendahnya tekanan udara yang masuk kedalam throttle body. Tujuan penelitian ini untuk meningkatkan kembali performa kendaraan. Penelitian ini menggunakan metode eksperimen yang dilakukan di Workshop Pengujian Kendaraan Teknik Otomotif UNP dengan menggunakan kendaraan Toyota Avanza 1300 CC, penelitian daya dan torsi dilakukan dengan menambahkan turbo cyclone. Pengambilan data penelitian dilakukan tiga kali pada tiap pengujian. Hasil penelitian yang telah dilakukan pada kendaraan Toyota Avanza 1300 CC. 1) Pemasangan turbo cyclone pada kemiringan 550, menjadi peningkatan daya paling besar yaitu sebesar 3,3 Kw / 4,422 Hp. 2) Pemasangan turbo cyclone pada kemiringan 65o, menjadi peningkatan torsi paling besar yaitu sebesar 7,3 Nm. Dari penggunaan turbo cylone sehingga membuat tekanan udara meningkat mempengaruhi torsi dan daya.
\end{abstract}

\section{Kata Kunci}

Toyota Avanza 1300 CC, Turbo cyclone, Torsi, Daya, Pressure Drop

\author{
${ }_{1,2}$ Jurusan Teknik Otomotif, Fakultas Teknik, Universitas Negeri Padang \\ Jl. Prof. Dr. Hamka Kampus UNP Air Tawar, \\ *ilham.zikri97@gmail.com \\ Submitted : May 17, 2021. Accepted : May 31, 2021. Published : May 31, 2021
}




\section{PENDAHULUAN}

Teknologi otomotif merupakan suatu hal yang menarik untuk dikembangkan karena semakin maju ilmu pengetahuan tentang motor bakar tentang pengaruh terhadap unjuk kerja motor bakar. Motor bakar merupakan alat yang dipakai untuk memberikan kemudahan manusia dalam melakukan aktivitas terutama pada sarana transportasi. [1] Umumnya motor bakar adalah mesin yang bekerja dengan gerakan translasi di dalam silinder. Motor bakar mempunyai perfoma dan karakter yang berbeda-beda, penyebabnya adalah kurangnya tekanan udara yang masuk ke dalam throttle body .

Salah satu teknologi otomotif yang berkembang sampai saat ini adalah penggunaan turbo cyclone pada motor bakar. [1] Turbo cyclone merupakan salah satu teknologi pemampatan udara, dengan cara udara melewati turbo cyclone supaya bisa dibuat pusaran yang lebih fokus. Pemasangan Turbo cyclone menyebabkan adanya perubahan karakteristik aliran udara. Antara lain yaitu timbulnya pressure drop dan turbulensi.

Belum adanya penelitian lebih lanjut yang menguji pengaruh turbo cyclone terhadap torsi dan daya pada Toyota Avanza 1300 CC, sehingga data yang didapatkan dirasa belum memenuhi kebutuhan informasi bagi mekanik.

\section{Motor Bensin}

Motor bensin merupakan mesin yang menggunakan bahan bakar besin dan udara, yang di mana penyalaannya menggunakan busi. Maka dari itu energi kimia menjadi energi gerak putar, yang di mana dapat diukur dengan Horse Power (HP).

Motor Bensin 4 Langkah (four stroke engine), [1] motor empat langkah merupakan motor yang membutuhkan dua kali putaran poros engkol untuk menyelesaikan satu kali siklus didalam silinder. Dengan kata lain, setiap silinder membutuhkan empat langkah torak pada dua putaran poros engkol untuk melengkapi siklusnya. Mesin empat tak memiliki langkah torak antara lain; langkah hisap, langkah kompresi, langkah kerja dan langkah buang.

\section{Sistem Bahan Bakar EFI (Electronic Fuel Injection)}

Maka dari itu energi kimia menjadi energi gerak Sistem bahan bakar injeksi atau Electronic Fuel Injection merupakan langkah inovasi yang dikembangkan untuk diterapkan pada kendaraan bermotor saat ini. Sistem bahan bakar EFI dimaksudkan agar dapat meningkatkan kinerja mesin supaya daya dan torsi yang dihasilkan lebih baik, akselerasi yang lebih responsif stabil pada setiap putaran mesin, pemakaian bahan bakar yang lebih irit.

[1] Menurut Hidayat sistem EFI memiliki sensor - sensor untuk mengetahui jumlah bahan bakar dan udara yang optimum disesuaikan dengan banyaknya dan suhu udara masuk, putaran mesin, sudut katup throttle, kadar oksigen di dalam exhaust manifold, dan kondisi penting lainnya dan [1] sistem EFI mengunakan konsep pencampuran udara dan bahan bakar terjadi pada saluran masuk (intake manifold) dengan mengunakan sebuah injektor untuk menyemprotkan bahan bakarnya. Pola pengaruran saat penyemprotan bahan bakar ke dalam intake manifold diatur oleh sebuah Electronic Control Unit (ECU). ECU akan mendapatkan beberapa sensor untuk meyemprotkan bahan bakar dengan saat dan jumlah yang tepat sesuai dengan putaran mesin. Perbandingan jumlah bahan bakar dan udara yang sesuai akan menyebabkan terjadinya pembakaran yang sempurna untuk menghasilkan tenaga yang optimal dan emisi gas buang yang ramah lingkungan.

\section{Turbo cyclone}

Turbo cyclone merupakan perangkat tambahan pada mesin pembakaran dalam (internal combustion engine) untuk mengubah aliran udara yang akan masuk ke dalam ruang bakar. [1] "Swirling vane terdiri dari sudu-sudu yang diam terbuat dari seng setebal 0,5 mm yang ditekuk dengan sudut 45 pada titik diagonalnya. Dengan lekukan sudu tersebut diharapkan fluida yang bergerak menyesuaikan dengan lekukan sudu. [1] Turbo cyclone ini mirip swirl fan 
yang sudu-sudunya tidak berputar (fixed Vane) dan ditempatkan pada saluran udara masuk dan atau pada intake manifold.

[1] Prinsip kerja turbo cyclone adalah angin yang masuk ke ruang bakar dibuat satu pusaran sehingga lebih tertuju pada satu titik dan proses pembakaran menjadi lebih sempurna . Udara yang melewati sudu-sudu tersebut membentuk pusaran sehingga percampuran bahan bakar dan udara menjadi lebih homogen. [1] Pemasangan Turbo cyclone menyebabkan adanya perubahan karakteristik aliran udara. Antara lain yaitu timbulnya pressure drop dan turbulensi.

\section{Sudut pada Turbo cyclone}

Sudut yang terdapat pada turbo cyclone dapat berupa $45^{0}$ sampai $65^{\circ}$. Setiap perubahan sudut sangat mempengaruhi kinerja mesin yang berdampak pada intensitas turbulensi dan pressure drop. Pada penelitian ini menggunakan sudut dengan kemiringan $45^{\circ}, 55^{\circ}$ dan $65^{0}$ sehingga diharapkan dapat membentuk aliran berputar (swirl) dan membuat tekanan udara masuk semakin meningkat. [1] Semakin tinggi sudut, maka aliran akan semakin tercampur, ini dapat dilihat dari indikasi pola streamline yang semakin berputar dan pergeseran warna distribusi kecepatan dan tekanan kedepan, serta nilai turbulence kinetic energy yang semakin tinggi, hal ini juga berdampak pada meningkatnya nilai pressure drop. Maka dengan melakukan perubahan bentuk sudut sudu pada turbo cyclone akan berdampak besar terhadap pressure drop dan intensitas turbulensi.

\section{Saluran Udara}

Saluran udara atau intake manifold adalah, part berbentuk pipa tabung yang terletak di bagian atas mesin, guna mengantarkan campuran udara dan bahan bakar ke silinder mesin agar digunakan untuk proses pembakaran.Laju aliran udara pada intake manifold dapat diklasifikasikan pada 2 tipe, yaitu:

[1] Aliran laminar ketika fluida mengalir pada lapisan (layer) tertentu dan tidak terjadi pertukaran (mixing) secara makroskopik diantara lapisan-lapisan fluida yang berdekatan. Awal mula aliran terbentuk berupa aliran laminer yang bergerak lurus sejajar mengikuti garis awal, viskositas (tingkat kekentalan) cukup tinggi, dan tingkat kecepatan fluida yang rendah. Aliran laminar cenderung tidak meningkatkan homogenitas, hal ini dikarenakan tidak ada perubahan aliran dalam menyatukan campuran udara dan bahan bakar, sehingga tidak diaplikasikan pada intake manifold. Sebagaimana ditunjukkan pada Gambar 1 aliran laminar dapat dianalogikan sebagai aliran lurus dan halus.

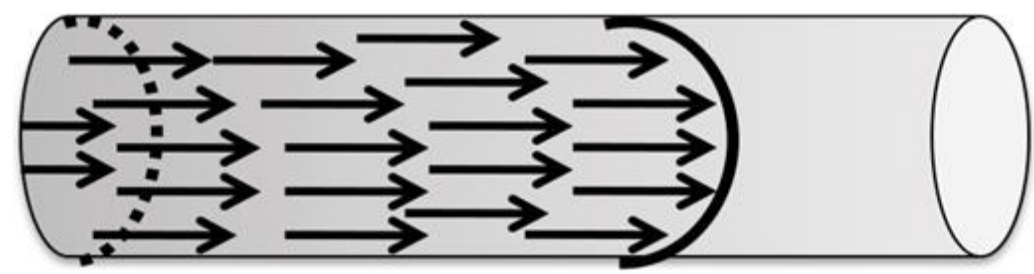

Gambar 1. Laju aliran laminer

[1] Apabila laju aliran ditingkatkan, filamen tinta menjadi tidak stbil dan berubah menjadi gerak acak. Garis yang dibentuk oleh filamen tinta menjadi seperti benang kusut, dan kondisi ini dengan cepat menyebar ke seluruh medan aliran. Pertukaran partikel fluida diantara lapisan yang berdekatan, menyebabkan tinta terdispersi dengan cepat. Perilaku aliran turbulen ini mengarah ke fluktuasi kecepatan, sehingga analisa aliran turbulen didasarkan pada gerak ratarata aliran. Aliran ini terjadi karena viskositas (kekentalan) pada fluida relatif lebih ringan bila dibandingkan dengan gaya inersia, sehingga memungkinkan terjadinya homogenitas pada campuran udara dan bahan bakar di dalam saluran hisap intake manifold, karena karakteristik aliran yang bergerak ke segala arah, terjadi pusaran fluida, dan tidak beraturan. 
[1] Secara kuantitatif, perbedaan antara aliran laminer dan turbulen bisa diketahui dengan menempatkan alat ukur kecepatan yang sensitif pada medan aliran. Untuk aliran laminer steady, kecepatan di satu titik tertentu tetap konstan terhadap perubahan waktu, sedangkan untuk aliran turbulen, grafik kecepatan menunjukkan bahwa kecepatan sesaat untuk, berfluktuasi secara acak.

\section{Parameter Kerja Mesin}

Parameter kerja mesin yang dibahas pada penelitian ini ialah specific power output yang meliputi torsi dan daya. Secara teori, kondisi mesin ditentukan dari torsi dan daya, semakin tinggi hasilnya maka kondisi mesin dalam keadaan baik.

\section{Torsi}

[1] Torsi adalah gaya pada gerak translasi menunjukkan kemampuan sebuah gaya untuk membuat benda melakukan gerak rotasi/berputar. Sebuah benda akan berotasi bila dikenai torsi. Kekuatan putar poros ini pada mesin dihasilkan oleh pembakaran yang efeknya mendorong piston naik turun. Piston naik turun menyebabkan poros engkol ikut berputar yang kemudian akan ditransfer menuju ke roda-roda penggerak sehingga mencapai ke roda. Terjadi ketika kendaraan akan bergerak (start) atau sewaktu mempercepat laju kendaraan, dan tenaga berguna untuk memperoleh kecepatan tinggi.

[1] Torsi merupakan ukuran dari kemampuan sebuah mesin untuk melakukan kerja. Besarnya torsi dapat ditentukan dengan mengukur beban mesin dan panjang lengan torsi. Pengukuran beban pada mesin dilakukan dengan dinamometer.

\section{Daya}

[1] Daya merupakan besarnya kerja telah dilakukan tiap satuan waktu, pada motor bensin, Brake Horse Power (BHP) merupakan besaran yang mengindikasikan horse power actual yang dihasilkan oleh mesin. [1] Selain itu "Daya kerja motor atau prestasi kerja motor adalah gerakan/putaran mesin yang menghasilkan kerja persatuan waktu".

Tabel 1. Spesifikasi Toyota Avanza 1300 CC

\begin{tabular}{|l|l|}
\hline \multicolumn{2}{|l|}{ Spesifikasi Toyota Avanza } \\
\hline Panjang & $4.140 \mathrm{~mm}$ \\
\hline Lebar & $1.660 \mathrm{~mm}$ \\
\hline Wheel base & $2.655 \mathrm{~mm}$ \\
\hline Ground clearance & $200 \mathrm{~mm}$ \\
\hline Transmisi & 5 -speed manual \\
\hline Sistem kemudi & Rack \& pinion with Electronic Power Steering (EPS) \& Tolt Steering \\
\hline Suspensi depan & MacPherson Strut with Coil Spring \\
\hline Suspensi belakang & 4 link lateral rod with coil spring \\
\hline Rem depan & Ventilated disc \\
\hline Rem belakang & Tromol \\
\hline Ukuran ban & $185 / 70$ R14 \\
\hline Tipe mesin & 4 cylinder, 16 V, DOHC, VVT-i \\
\hline Bahan bakar & Bensin \\
\hline Sistem & Electronic Fule Injection (EFI) \\
\hline Kapasitas tangki & 45 liter \\
\hline Kode mesin & K3-VE \\
\hline Daya maksimum & 92 PS di 6.000 rpm \\
\hline Torsi maksimum & 11,9 kgm di 4.400 rpm \\
\hline
\end{tabular}

Sumber: (ikh n.d.) 


\section{METODE PENELITIAN}

Penelitian ini merupakan penelitian eksperimen. Di gunakan untuk mencari tau pengaruh antara variabel turbo cyclone, variabel torsi dan variabel daya serta menjawab pertanyaan penelitian. Penelitian eksperimen yaitu memberikan sebuah treatment atau sebuah perlakuan pada objek lalu diadakan evaluasi untuk melihat pengaruh dan perubahanya.

Adapun yang menjadi objek penelitian ini adalah Toyota Avanza 1300 CC tahun 2015, spesifikasi dari objek penelitian seperti tertera ppada tabel 1.

Pada penelitian ini yang akan menjadi fokus penelitian adalah pengukuran daya dan torsi Toyota Avanza 1300 CC tahun 2015 dengan dynamometer. Pengukuran pertama dilakukan tanpa pemasangan turbo cyclone (kondisi standar) dan perlakuan kedua setelah dipasangkan turbo cyclone di iringi dengan pengukuran pressure drop. Sebelum pengukuran dilakukan, kendaraan yang digunakan diservice terlebih dahulu sesuai standar dari pabrikan. Durasi untuk masing-masing pengukuran direncanakan hingga mesin mencapai daya dan torsi maksimum.

Teknik pengambilan data adalah pengambilan data secara langsung di Workshop Pengujian Kendaraan Jurusan Teknik Otomotif Fakultas Teknik. Pengujian daya dan torsi menggunakan alat dynamometer, yang berguna untuk mengukur daya dan torsi yang diuji sebanyak 3 (tiga) kali.

\section{HASIL DAN PEMBAHASAN}

\section{Hasil}

Dari gambar grafik dapat diketahui bahwa terjadi peningkatan daya pada penggunaan turbo cyclone di kemiringan $55^{\circ}$, namun untuk penggunaan turbo cyclone di kemiringan lainnya tidak terjadi peningkatan signifikan. Hal ini terbukti ketika motor bakar dengan bahan bakar pertamax standar menghasilkan daya maksimum sebesar $87.1 \mathrm{Kw}$ pada putaran mesin 6178 rpm. Sedangkan ketika motor bakar menggunakan turbo cyclone di kemiringan $55^{0}$ daya maksimum yang dihasilkan sebesar 90,4 Kw pada putaran mesin $6277 \mathrm{rpm}$.

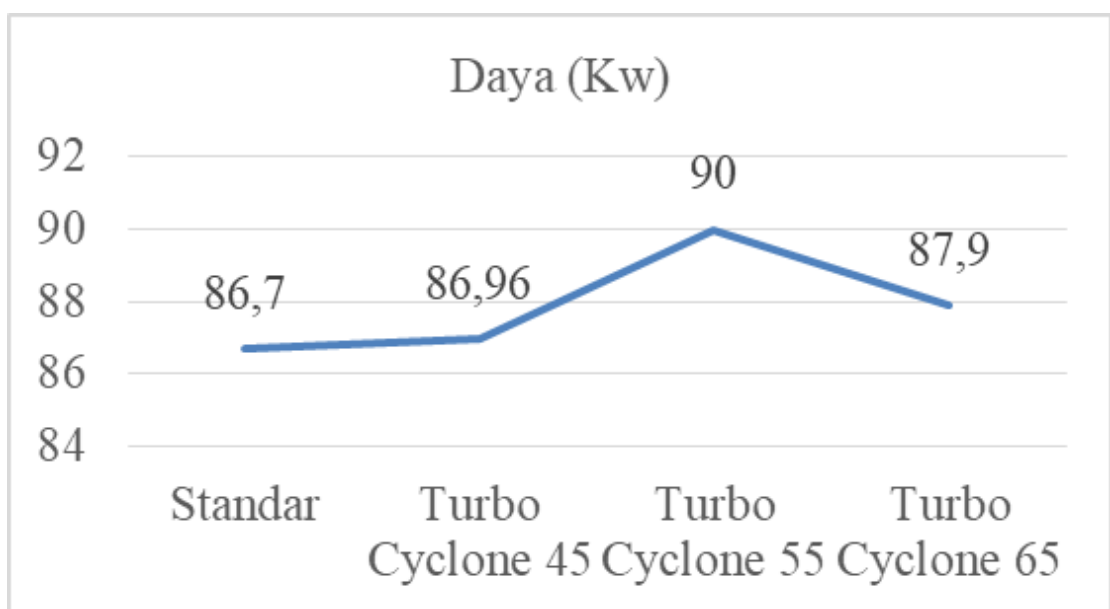

Gambar 2. Grafik hasil pengujian daya sebelum dan sesudah menggunakan turbo cyclone pada Toyota Avanza 1300 CC

Dari grafik gambar 2 dapat diketahui bahwa terjadi peningkatan torsi pada penggunaan turbo cyclone di kemiringan $65^{\circ}$, namun untuk penggunaan turbo cyclone di kemiringan lainnya tidak terjadi peningkatan signifikan. Hal ini terbukti ketika motor bakar dengan bahan bakar pertamax standar menghasilkan torsi maksimum sebesar 144,1 Nm pada putaran mesin 4754 
rpm. Sedangkan ketika motor bakar menggunakan turbo cyclone di kemiringan $65^{0}$ torsi maksimum yang dihasilkan sebesar 154,6 Kw pada putaran mesin $4357 \mathrm{rpm}$.

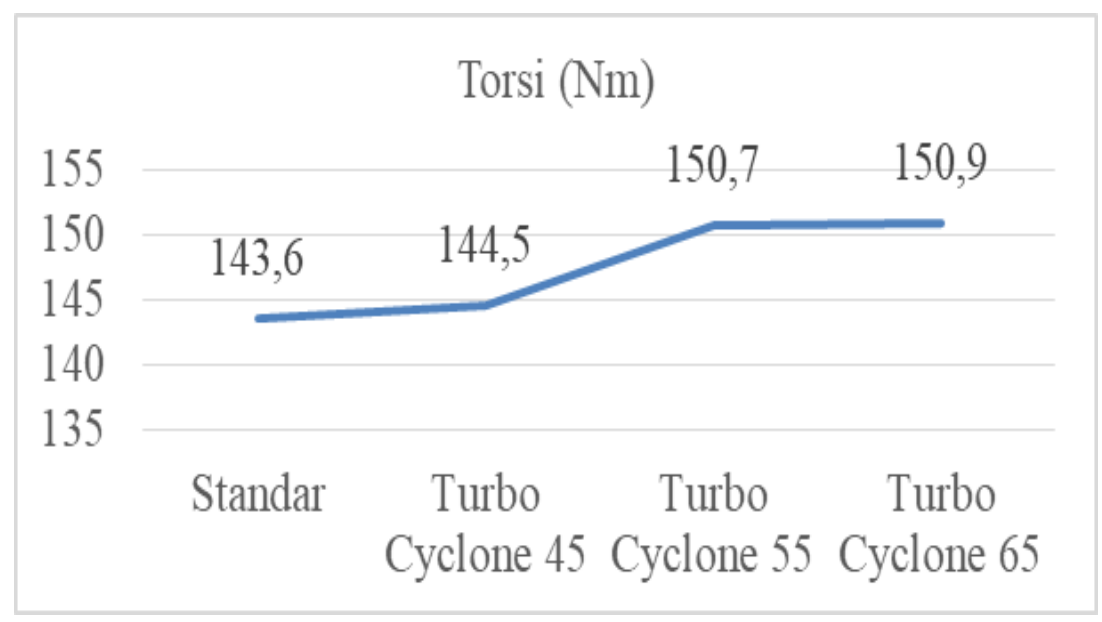

Gambar 3. Grafik hasil pengujian torsi sebelum dan sesudah menggunakan turbo cyclone pada Toyota Avanza 1300 CC

Dari grafik gambar 3, penggunaan turbo cyclone pada kemiringan $55^{0}$ menghasilkan tekanan terendah. Hal ini dibuktikan motor bakar menggunakan turbo cyclone kemiringan $55^{0}$ menghasilkan MAP maksimum 8,0 inHg pada putaran mesin 750 RPM, motor bakar standar menghasilkan MAP maksimum 8,6 inHg pada putaran mesin 750 RPM. Motor bakar menggunakan turbo cyclone kemiringan $45^{0}$ menghasilkan MAP tertinggi yaitu 8,3 inHg pada putaran mesin 3000 RPM, motor bakar standar menghasilkan MAP maksimum 8,0 inHg pada putaran mesin 3000 RPM, pada putaran mesin yang sama penggunaan turbo cyclone kemiringan $55^{0}$ menghasilkan MAP maksimum 7,7 inHg.

Dari hasil analisis pengujian motor bakar standar hingga menggunakan turbo cyclone yang sudah dilakukan, maka didapatkan pembahasan tekanan efektif rata-rata yang maksimum pada putaran 3000 RPM. Turbo cyclone dengan kemiringan $55^{\circ}$ yang digunakan pada motor bakar Toyota Avanza 1300 CC mampu menambah tekanan efektif rata-rata pada motor bakar standa. Namun penggunaan turbo cyclone dengan kemiringan lain pada motor bakar Toyota Avanza 1300 CC cenderung tidak mengalami perubahan yang signifikan dari kondisi motor bakar standar.

Tabel 2. Hasil Pengujian Pembacaan Manifold Absolute Pressure Sensor

\begin{tabular}{|l|l|l|l|l|l|}
\hline \multirow{2}{*}{ NO } & \multirow{5}{*}{ RPM } & \multicolumn{4}{|l|}{ PEMBACAAN MANIFOLD ABSOLUTE PRESSURE } \\
\cline { 3 - 6 } & & SENSOR (MAP) satuan (inHg) & \\
\cline { 3 - 6 } & & STANDARD & $45^{0}$ & $55^{0}$ & $65^{0}$ \\
\hline 1 & 750 & 8,6 & 8,5 & 8,0 & 8,6 \\
\hline 2 & 1500 & 7,7 & 7,5 & 7,1 & 7,4 \\
\hline 3 & 2000 & 7,7 & 7,5 & 7,4 & 7,4 \\
\hline 4 & 3000 & 8,0 & 8,3 & 7,7 & 8,0 \\
\hline 5 & 4000 & 7,4 & 7,4 & 7,1 & 7,3 \\
\hline 6 & 5000 & 7,3 & 7,3 & 7,0 & 7,1 \\
\hline 7 & 6000 & 7,1 & 7,0 & 6,8 & 6,9 \\
\hline
\end{tabular}




\section{Pembahasan}

Penggunaan turbo cyclone sebelum throttle body menyebabkan terjadinya perubahan aliran, dari laminer menjadi turbulen. Sesuai dengan penjelasan sebelumnya, aliran turbulen mempunyai karakteristik bergerak ke segala arah, terjadi pusaran fluida dan tidak beraturan. Hal itu mengakibatkan meningkatkan tekanan udara di dalam throttle body, sehingga ketika pembukaan katub throttle body terjadi penurunan kevakuman dalam intake manifold yang dibaca oleh MAP. Hasil MAP menstimulus ECU untuk meningkatkan debit bahan bakar. Semakin besar bahan bakar digunakan maka semakin meningkatlah daya yang di hasilkan

Sebelum membahas penggunaan turbo cyclone $55^{\circ}$ dapat kita lihat turbo cyclone $45^{0}$ memiliki gaya hambat yang lebih tinggi sehingga aliran udara masuk tidak stabil, hal itu yang menyebabkan peningkatan daya tidak terlalu signifikan. Sementara turbo cyclone $65^{0}$ memilliki gaya hambat yang lebih kecil dibandingkan kemiringan lainnya, sehingga hambatan pada aliran udara masuk juga sangat kecil. Kecilnya hambatan membuat aliran udara tidak terlalu berpusar, hal itu yang menyebabkan peningkatan daya tidak terlalu signifikan. Turbo cyclone $55^{0}$ merupakan, turbo cyclone dengan sudut paling efisien dalam membentuk pusaran fluida, hambatan yang terjadi sesuai dengan kebutuhan pemusaran fluida, hal itu juga yang menyebabkan peningkatan daya signifikan.

Pengambilan data pada RPM 6200 sesuai dengan pengertian daya yang berkaitan dengan kecepatan dan putaran atas mesin. Toyota Avanza 1300 CC memiliki RPM tertinggi 6500 RPM. Sehingga benar pengambilan data daya harusnya pada RPM 6200, karena disitu ditapati puncak daya tertinggi yang dihasilkan mesin atau bisa dibilang putaran atas mesin Toyota Avanza 1300 CC yang dijadikan objek.

Torsi adalah ukuran kemampuan mesin untuk melakukan kerja. Torsi berguna pada waktu kendaraan akan bergerak, sewaktu mempercepat laju kendaraan maupun untuk memperoleh kecepatan tinggi. Pengaruh dari torsi ialah "sebuah benda bisa berputar terhadap porosnya dan benda itu dapat berhenti jika terjadi gaya berlawanan dengan nilai yang sama besar".

Turbo cyclone $65^{\circ}$ merupakan turbo cyclone dengan kemiringan sudut tertinggi dan memilliki gaya hambat yang lebih kecil dibandingkan kemiringan lainnya, sehingga hambatan pada aliran udara masuk juga sangat kecil.

Dapat disimpulkan, dengan kemiringan sudut semakin tinggi, maka gaya hambat menjadi lebih kecil, seperti pengertian di atas benda itu dapat berhenti jika terjadi gaya yang berlawanan dengan nilai sama besar. Dengan penjelasan ini, dapat disebutkan bahwa turbo cyclone $65^{0}$ merupakan sudut turbo cyclone terbaik dalam peningkatan torsi.

Pemasangan turbo cyclone pada throttle body dikarenakan, jika turbo cyclone di pasang sebelum saringan udara, aliran udara yang telah dibentuk oleh turbo cyclone akan kembali tidak beraturan karena sebelum memasuki throttle body, udara akan melewati filter terlebih dahulu. Sementara pada intake manifold tidak terdapat dudukan yang tepat sehingga kemungkinan turbo cylone terhisap ke dalam mesin sangat besar, dan sensor MAP berada sesudah throttle body sehingga kevakuman udara tidak terbaca dan tidak akan di dapati pengaruh penggunaan turbo cyclone.

Sesuai dengan guna turbo cyclone itu sendiri ialah peningkatan performa mesin dengan membentuk pusaran udara dengan cara mengubah karakteristik aliran udara yang akan masuk ke throttle body sehingga menimbulkan pressure drop dan turbulensi.

Penggunaan turbo cyclone sebelum throttle body menyebabkan terjadinya perubahan aliran, dari laminer menjadi turbulen. Hal itu mengakibatkan meningkatkan tekanan udara di dalam throttle body, sehingga ketika pembukaan katub throttle body terjadi penurunan kevakuman dalam intake manifold yang dibaca oleh MAP. Hasil MAP menstimulus ECU untuk meningkatkan debit bahan bakar. Semakin besar bahan bakar digunakan maka semakin meningkatlah daya dan torsi yang di hasilkan. 


\section{SIMPULAN DAN SARAN}

\section{Simpulan}

Berdasarkan hasil pengujian yang telah dilakukan dapat disimpulkan beberapa hal. Penelitian yang telah dilakukan pada Toyota Avanza 1300CC didapatkan hasil bahwa pemasangan turbo cyclone pada kemiringan $55^{\circ}$, menjadi peningkatan paling besar di banding kemiringan yang lain yaitu sebesar 3,3 Kw / 4,422 Hp.

Penelitian yang telah dilakukan pada Toyota Avanza 1300CC, didapatkan hasil bahwapemasangan turbo cyclone pada kemiringan $65^{\circ}$, menjadi peningkatan paling besar di banding kemiringan yang lain yaitu sebesar 7,3 $\mathrm{Nm}$.

\section{Saran}

Berdasarkan hasil penelitian yang telah dibahan dan diuraikan, maka penulis menyarankan beberapa hal. Penelitian ini masih terbatas pada objek penelitian Toyota Avanza 1300 CC, sehingga dirasa perlu untuk melakukan treatment yang sama pada kendaraan lain. Agar tidak menghilangkan atau mengganti nama alat yang sudah peneliti buat.

\section{DAFTAR RUJUKAN}

[1] M. S. A. Ihwanudin and A. Martiningsih, "Penggunaan turbo cyclone pada kendaraan bermotor terhadap emisi gas buang CO dan HC," Jurnal teknologi, Kejuruan dan Pengajarannya, vol. 38, no. 2, pp. 113-120, 2015.

[2] M. Khoir and Marsudi, "Pengaruh penggunaan turbo cyclone dan busi iridium terhadap performa motor Honda supra x 125 cc tahun perakitan 2011," JTM, vol. 2, no. 2, pp. 79-88, 2014.

[3] J. Susilo, "Modifikasi Cylinder Head Terhadap Unjuk Kerja Sepeda Motor," Jurnal Teknik Mesin UBL, vol. 3, no. 1, pp. 19-23, 2015.

[4] N. A. Mufarida, "Analisis Prestasi Kerja Motor 4 Tak Dengan Penggunaan Turbo Cyclone," J-Proteksion, vol. 1, no. 1, pp. 1-7, 2016.

[5] S. Buyung, "Analisis Perbandingan Daya dan Torsi pada Alat Pemotong Rumput Elektrik (APRE)," Jurnal Voering, vol. 3, no. 1, pp. 1-4, 2018.

[6] Y. Effendi and Rifal, "Uji Performa Mesin Diesel Satu Silinder Menggunakan Metode Standar Nasional Indonesia (SNI) 0119 : 2012," Jurnal Teknik Mesin Universitas Muhammadiyah Tangerang, vol. 2, no. 1, pp. 1-7, 2018.

[7] Y. R. Fauzi, "Pengaruh Penambahan Turbo Cyclone Aksial Terhadap Aliran Dan Performa Motor Bakar," Jurnal Teknik Mesin Univ. Muhammadiyah Metro, vol. 7, no. 1, pp. 26-27, 2018.

[8] B. D. S. K. Supriyatmojo, W. T. Putra and K. Winangun, "Pengaruh Penggunaan Tiga Metode Injector Cleaner Terhadap Emisi Gas Buang Dan Konsumsi Bahan Bakar Pada Honda Vario Injeksi 125," Repository, vol. 2, no. 2, pp. 23-34, 2018.

[9] T. Sugiarto, "Analisa Kerja Manifold Absolute Pressure (Map) Dan Kadar Kandungan Emisi Gas Buang Yang Dihasilkan Pada Motor Bensin Dengan Sistem Injeksi Elektronik Type DEFI," Jurnal Elektron, vol. 5, no. 2, pp. 69-74, 2013.

[10] R. d. A. S. Faturachman, "Pengembangan Desain Intake Tromp Cyclone Dengan Menggunakan Computational Fluid Dynamic," Jurnal Ilmiah Program Studi Magister Teknik Mesin, vol. 10, no. 1, pp. 47-52, 2020. 